\title{
O IMPACTO DA SAÚDE NO TURISMO: UMA ANÁLISE ATRAVÉS DOS DADOS DOS ESTADOS BRASILEIROS.
}

\author{
A.M.V. da Silva ${ }^{1}$, J.L.Soares Sobrinho² e R.G.Arruda ${ }^{3}$. \\ 1 Universidade Federal de Pernambuco, Centro de Ciências Sociais e Aplicadas, \\ Programa de Pós Graduação em Gestão e Economia da Saúde. \\ ${ }^{2}$ Universidade Federal de Pernambuco, Centro de Ciências da Saúde, Departamento de \\ Ciências Farmacêuticas. \\ ${ }^{3}$ Faculdade Nova Roma. \\ Email pra contato: amandavaldevino.ufpe@gmail.com
}

RESUMO - Esta pesquisa apresenta por objetivo principal investigar o impacto da saúde sobre o turismo no Brasil, através de análises de dados de desembarques nos estados brasileiros e de incidência e óbitos ocasionados pela dengue. Para isso, será realizada uma análise de regressão em dados em painel, onde serão utilizados dados longitudinais que acompanham as características dos estados dentro de um intervalo determinado de tempo. Este estudo espera concluir que a saúde tem afetado o turismo no Brasil, e que isso pode ser demonstrado através da estimação da incidência da dengue no turismo dos estados brasileiros, demonstrando assim o seu grau de correlação.

Palavras-chaves: Desembarques; Dengue; Óbitos.

ABSTRACT - The main objective of this research is to investigate the impact of health on tourism in Brazil, through data analysis of landings in the Brazilian states and of incidence and deaths caused by dengue. For this, a regression analysis will be performed on panel data, where longitudinal data will be used that accompany the characteristics of the states within a determined interval of time. This study hopes to conclude that health has affected tourism in Brazil, and that this can be demonstrated by estimating the incidence of dengue in tourism in Brazilian states, thus demonstrating its degree of correlation.

Keywords: Landings; Dengue; Deaths.

\section{INTRODUÇÃO}

A atividade turística é considerada uma das que mais contribuem para o funcionamento da economia, tanto do Brasil quanto do mundo. Este setor se destaca também na geração de renda e emprego nas diversas localidades onde ele está inserido, contribuindo assim para o crescimento econômico e social do local. Nota-se também que, com a globalização e os recentes avanços tecnológicos, o setor pode proporcionar muitos benefícios econômicos, sociais, culturais e ambientais para a sociedade. Com base em sua relevância para a economia, naturalmente existe interesse no desenvolvimento do turismo bem como em fatores que possam ocasionar sua diminuição ou alteração de fluxo de 
turistas. O conhecimento desses fatores e sua relação com o turismo pode fornecer dados gerenciais para entidades públicas e privadas, ou formulação de políticas e estratégias objetivando análise, compreensão e decisões com intuito de prevenir ou atenuar o impacto no setor, em âmbito local e nacional.

Para Costa (2004) com o passar do tempo percebeu-se que, para tornar um destino turístico cada vez mais atrativo, se fazia necessário atentar para fatores além dos investimentos em construções de equipamentos hoteleiros, parques turísticos, aeroportos e estradas. É inegável a importâncias dos investimentos citados, porém, além da infraestrutura turística, os destinos precisam ofertar também segurança e meio ambiente sadio, que fazem parte do planejamento turístico. Como um dos fatores que pode influenciar o recebimento de turistas nos destinos escolhidos, a saúde pública ambiental deve ser monitorada constantemente, a fim de evitar epidemias de doenças, que poderão causar impacto no turismo local.

Em complemento ao autor anterior, Carvalho e Pimentel (2012) ressaltam que as epidemias e pandemias podem ser classificadas como fatores aleatórios, podendo ser descritos como ocorrências de diferentes naturezas que não podem ser previstos, ou se forem antecipados não podem ser controlados, de forma que afetam intensamente os fluxos turísticos em um primeiro momento. Apenas em seguida é possível desenvolver estratégias para combatê-los, como tem ocorrido com a dengue no Brasil.

Dessa forma, esta pesquisa apresenta por objetivo principal investigar o impacto da saúde sobre o turismo no Brasil, através de análises de dados de desembarques nos estados brasileiros e de incidência e óbitos ocasionados pela dengue.

Tal pesquisa se justifica pelo fato de que o turismo é um mercado caracterizado por um crescimento quase constante e conseqüentemente uma participação interessante na economia global e local. Por outro lado, as doenças tropicais têm sido bastante observadas e estudadas pelos pesquisadores brasileiros. Entre elas, a que tem apresentado maior significância, em termos de notificação de casos é a dengue, em seus quatro sorotipos. Dessa forma, com base nesse breve histórico, considerou-se a importância da investigação da correlação entre os dois fatores citados anteriormente.

\section{MATERIAIS E MÉTODOS}

Visando alcançar o objetivo indicado na primeira seção, optou-se por reunir os dados referentes aos desembarques internacionais e domésticos em cada estado brasileiro, disponibilizados através do site do Ministério do Turismo (MTur). Além desses, reuniuse os dados de ocorrência da dengue em cada estado, e da quantidade desses casos que evoluiu para óbito, todos esses disponibilizados no Sistema de Informação de Agravos de Notificação (SINAN).

Para complementar o banco de dados, reuniu-se ainda informações sobre a população e produto interno bruto de cada estado. Ressalta-se aqui que o período analisado compreende de 2003 a 2014, que representa a janela de tempo onde se obteve a quantidade total de dados para todas as variáveis.

Este estudo busca estimar o efeito da incidência da dengue sobre a taxa de desembarques nos estados brasileiros. Para isso, será realizada uma análise de regressão em dados em painel, onde, segundo Duarte et al (2007) a metodologia dos modelos para Dados em Painel, consiste de observações de $n$ entidades para dois ou mais períodos de tempo. Ainda segundo os autores, esse tipo de dados combina características de séries temporais com dados em corte transversal e são amplamente utilizados em estudos econométricos e nas ciências sociais aplicadas. Dessa forma, serão utilizados dados 
longitudinais que acompanham as características dos estados dentro de um intervalo determinado de tempo, conforme variáveis identificados no quadro 1.

Quadro 1 - Variáveis utilizadas na pesquisa

\begin{tabular}{|l|l|l|}
\hline Variável dependente & Variável independente & Variáveis controles \\
\hline $\begin{array}{l}\text { Quantidade de } \\
\text { desembarques por estado } \\
\text { por ano }\end{array}$ & $\begin{array}{l}\text { Número de óbitos de cada } \\
\text { estado por ano }\end{array}$ & $\begin{array}{l}\text { Características dos estados } \\
\text { (PIB, população) }\end{array}$ \\
\hline
\end{tabular}

\section{RESULTADOS E DISCUSSÃO}

Buscando atender o objetivo definido para esta pesquisa elaborou-se um banco de dados contendo os dados pertinentes a cada estado durante o período de tempo já definido. Dessa forma, seguem-se os resultados obtidos até o presente momento.

De acordo com a seleção dos dados pode-se observar na tabela 1, o número crescente de desembarques em três estados brasileiros, conhecidos como destinos turísticos, corroborando com a informação divulgada pelo Ministério do Turismo onde pontua um crescimento expressivo do setor entre 2003 e 2009, superando o crescimento total da economia no mesmo período.

Tabela 1 - Desembarques nos estados por período

\begin{tabular}{cccc} 
Estados & $\mathbf{2 0 0 3}$ & $\mathbf{2 0 0 8}$ & $\mathbf{2 0 1 4}$ \\
\hline Ceará & 944.689 & 1.758 .437 & 3.438 .036 \\
\hline Rio de Janeiro & 5.247 .566 & 7.150 .029 & 13.868 .768 \\
$\begin{array}{c}\text { Rio Grande do } \\
\text { Sul }\end{array}$ & 1.385 .397 & 2.280 .453 & 4.237 .561 \\
\hline
\end{tabular}

Em concordância com Costa (2014), que ressalta a perda de entrada de capital estrangeiro como uma das conseqüências da possível mudança do fluxo de turistas ocasionado pela incidência da dengue, em especial nos países da América Central e Latina, locais estudados por ele, pode-se observar a incidência da dengue nos estados citados anteriormente e no mesmo período na Tabela 2.

Tabela 2 - Incidência / óbitos da / por dengue por período

\begin{tabular}{cccc}
\hline Estados & $\mathbf{2 0 0 3}$ & $\mathbf{2 0 0 8}$ & $\mathbf{2 0 1 4}$ \\
\hline Ceará & $33182 / 21$ & $54661 / 32$ & $22756 / 51$ \\
\hline Rio de Janeiro & $5470 / 0$ & $235353 / 239$ & $7717 / 10$ \\
Rio Grande do & $59 / 0$ & $138 / 0$ & $153 / 0$ \\
Sul & & & \\
\hline
\end{tabular}




\section{CONCLUSÃO}

Este estudo espera concluir que a saúde tem afetado o turismo no Brasil, e que isso pode ser demonstrado através da estimação do efeito da incidência da dengue no turismo dos estados brasileiros, demonstrando assim o seu grau de correlação.

Espera-se também sugerir estratégias para combater de forma cada vez mais efetiva o impacto da doença em questão no setor turístico, que afeta conseqüentemente a economia brasileira.

\section{REFERÊNCIAS}

CARVALHO. FCC de, PIMENTEL. TD. A influência dos fatores externos sobre os destinos turísticos. IX Seminário da Associação Nacional Pesquisa e Pós-Graduação em Turismo 2012. Disponível em:

https://www.researchgate.net/publication/282649372 A Influencia dos Fatores Ambi entais Externos sobre os Destinos Turisticos $>$ Acesso em 13 out. 17

COSTA. Guilherme Antonio de Moura. O impacto econômico do dengue no turismo. Turismo em Análise, v. 15, n. 01, p. 13-21, maio 2004. Disponível em: $<$ http://www.revistas.usp.br/rta/article/viewFile/63685/66448> Acesso em 09 out. 17.

DUARTE, Patrícia C.; LAMOUNIER, Wagner M.; TAKAMATSU, Renata T. Modelos econométricos para dados em painel: aspectos teóricos e exemplos de aplicação à pesquisa em contabilidade e finanças. In: CONGRESSO USP DE CONTROLADORIA E CONTABILIDADE, 7.; CONGRESSO USP DE INICIAÇÃO CIENTÍFICA EM CONTABILIDADE, 4. 2007, São Paulo. Anais... São Paulo, 2007. p. $1-15$. Disponível em: $<$ https://edisciplinas.usp.br/pluginfile.php/176819/mod resource/content/1/Artigo\%20\%20Modelos\%20em\%20Painel.pdf> Acesso em: 26 nov 2017.

\section{AGRADECIMENTOS}

Agradecemos aqui ao Ministério do Turismo, ao Ministério da Saúde e ao Instituto Brasileiro de Geografia e Estatística, por disponibilizarem em seus sítios as informações necessárias para a construção dos bancos e dados, e por conseqüência a análise dos dados obtidos. 